\title{
Identification of individuals susceptible to high-altitude pulmonary oedema at low
} altitude

\author{
C. Dehnert*, ${ }^{\star}$, E. Grünig ${ }^{\#,}$, D. Mereles ${ }^{\#}$, N. von Lennep* and P. Bärtsch*
}

ABSTRACT: Individuals susceptible to high-altitude pulmonary oedema (HAPE) are characterised by an abnormal increase of pulmonary artery systolic pressure (PASP) in hypoxia and during normoxic exercise, reduced hypoxic ventilatory response, and smaller lung volume.

In 37 mountaineers with well-documented altitude tolerance, it was investigated whether any combination of these noninvasive measurements, including exercise in hypoxia, could improve the identification of HAPE-susceptible subjects at low altitude.

HAPE-susceptible subjects showed a significant higher increase of PASP during hypoxia at rest $(48 \pm 10 \mathrm{mmHg})$ compared with controls $(38 \pm 3 \mathrm{mmHg})$, as well as during normoxic exercise $(57 \pm 14$ versus $38 \pm 7 \mathrm{mmHg})$ and hypoxic exercise $(69 \pm 13$ versus $49 \pm 8 \mathrm{mmHg})$. PASP could not be assessed in three and eight subjects during normoxic or hypoxic exercise, respectively, due to insufficient Doppler profiles or systemic arterial hypertension. Sensitivity (77-94\%) and specificity (76-93\%) were not significantly different between the various testing conditions. Additional assessment of hypoxic ventilatory response and lung function parameters did not improve identification of HAPE-susceptible subjects in a multivariate analysis.

Due to the greater number of missing values in pulmonary artery systolic pressure measurements during hypoxic exercise, it was concluded that pulmonary artery systolic pressure measurements at rest during hypoxia or exercise in normoxia are most feasible for the identification of high-altitude pulmonary oedema-susceptible subjects.

KEYWORDS: Doppler echocardiography, exercise, hypoxia, hypoxic ventilatory response, lung volumes, pulmonary artery pressure

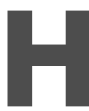
igh-altitude pulmonary oedema (HAPE) is a noncardiogenic pulmonary oedema that occurs at an altitude of $4,559 \mathrm{~m}$ in up to $6 \%$ of otherwise healthy unselected subjects [1]. Altitude, speed of ascent, pre-acclimatisation and, above all, individual susceptibility are determinants for its occurrence. The combination of fast ascent and susceptibility to HAPE increases the incidence of HAPE at $4,559 \mathrm{~m}$ to $\sim 60 \%$ [1]. Since HAPE is a life-threatening condition, it would be helpful to identify HAPE-susceptible subjects at low altitude, particularly in those with no previous altitude exposure.

It has been widely demonstrated that increased hypoxic pulmonary vasoconstriction leading to abnormally high pulmonary artery pressure is the major contributor in the development of HAPE. The crucial role of high pulmonary artery pressure is confirmed by elevated pulmonary artery pressures in patients with HAPE [2-4], enhanced pulmonary vasoconstrictive response in HAPE-susceptible subjects to acute hypoxia [5-8] or exercise in normoxia $[6,7,9]$. It is also confirmed by the fact that interventions decreasing pulmonary artery pressure are effective in the treatment [10, 11] and prevention [4] of HAPE. A previous study suggested that pulmonary artery systolic pressure (PASP) does not exceed $40 \mathrm{mmHg}$ in healthy subjects during acute hypoxic exposure (inspiratory oxygen fraction $\left.\left(\mathrm{FI}, \mathrm{O}_{2}\right) 0.12\right)$ or graded exercise in normoxia, and that subjects susceptible to HAPE have an increase of PASP above $40 \mathrm{mmHg}$ under either condition [7]. Since PASP rises markedly during acute hypoxic exposure and also during exercise in normoxia in HAPE-susceptible subjects compared with controls, it was hypothesised that combination of hypoxia and exercise may potentiate a pulmonary vascular response. Therefore, PASP should increase more in HAPE-susceptible subjects than in healthy controls and possibly improve discrimination between both groups.

\section{AFFILIATIONS}

*Division of Sports Medicine, and \#Dept of Cardiology, Internal Medicine, University Hospital, Heidelberg, Germany.

"Authors contributed equally to the study.

CORRESPONDENCE

C. Dehnert

Dept of Internal Medicine VII Sports Medicine

University Hospital Heidelberg Im Neuenheimer Feld 410 69120 Heidelberg Germany

Fax: 496221566931

E-mail: christoph.dehnert@med.uniheidelberg.de

Received:

June 132004

Accepted after revision:

October 312004 
Low hypoxic ventilatory response (HVR) is also associated with susceptibility to HAPE. Most studies report positive associations $[8,12,13]$, although one study found no relationship between HAPE and HVR [14]. Furthermore, some studies have reported associations between susceptibility to HAPE and lower vital capacity $[8,9,15,16]$ or lower functional residual capacity [16].

The aim of this study was to validate previous findings in another group of subjects and to test the following: 1) whether the combination of exercise and hypoxia are additive regarding the rise of PASP in subjects susceptible to HAPE; 2) whether this increase allows a better discrimination of subjects susceptible or resistant to HAPE; and 3) if including measurements of further markers of HAPE susceptibility (HVR, lung volume) would improve identification of HAPE-susceptible subjects.

\section{METHODS}

The study was performed in Heidelberg, Germany, at an altitude of $100 \mathrm{~m}$ above sea level. The study protocol was approved by the Ethics Committee of the Medical Faculty of the University of Heidelberg.

\section{Study population}

A total of 37 mountaineers (13 female and 24 male) participated in the study after they had given informed consent. Altitude tolerance was well documented in all of them from previous studies [3, 4, 10, 11] between 1986 and 2000, performed at the Margherita hut, situated at 4,559 $\mathrm{m}$ on the mountain range of Monte Rosa in the Swiss-Italian alps. In these studies, subjects ascended within 20-24 h from sea level to $4,559 \mathrm{~m}$, staying overnight at 3,611 m (Gniffetti hut, Monte Rosa mountain range). Subjects were classified as susceptible if they developed HAPE, or as HAPE resistant (control group) if they did not develop HAPE and had a negative history. The groups were matched for age and body mass index as accurately as possible, and there were no significant differences between groups with regard to these parameters (table 1). All subjects were natives of low altitude and had not resided above 2,000 $\mathrm{m}$ during the 2 weeks before examination. HAPE-susceptible subjects had experienced 2-4 episodes of radiographically documented HAPE. Characteristics of all subjects in which PASP determination was possible, at least during resting conditions, are presented in table 1.

\section{Normobaric hypoxia}

Measurements in hypoxia were performed in a hypoxic room in normobaric hypoxia with an $\mathrm{FI}_{1} \mathrm{O}_{2}$ of $12 \%$ corresponding to an environmental partial pressure of oxygen at $4,500 \mathrm{~m}$.

\section{Determination of pulmonary artery systolic pressure}

PASP can be reliably measured by echocardiography [17]. Two-dimensional and Doppler echocardiographic recordings were obtained with conventional equipment (SSD 2200; Aloka, Tokyo, Japan) and a $2.5 \mathrm{MHz}$ duplex transducer by experienced cardiac sonographers, who were blinded to the subjects' history of altitude tolerance. Measurements of PASP were recorded in normoxia at rest, during exercise in normoxia, and at rest and during exercise while exposed to hypoxia. Both exercise tests were performed on a bicycle ergometer in supine position, as described previously [7]. Initial workload was

\begin{tabular}{|c|c|c|c|}
\hline & HAPE susceptible & Control & p-value \\
\hline Age yrs & $53 \pm 9$ & $46 \pm 17$ & 0.17 \\
\hline Body mass index & $23.8 \pm 2.4$ & $22.4 \pm 2.4$ & 0.11 \\
\hline $\mathbf{W} \max \mathbf{W} \cdot \mathbf{k g}^{-1}$ & $2.9 \pm 0.5$ & $2.8 \pm 0.6$ & 0.86 \\
\hline fc, $\max \min ^{-1}$ & $153 \pm 12$ & $158 \pm 17$ & 0.33 \\
\hline TLC \% pred & $104 \pm 11$ & $107 \pm 10$ & 0.53 \\
\hline VC \% pred & $106 \pm 11$ & $107 \pm 13$ & 0.81 \\
\hline FEV $_{1} \mathrm{~L}$ & $3.6 \pm 0.6$ & $3.3 \pm 0.8$ & 0.28 \\
\hline MEF50 L. $\mathrm{s}^{-1}$ & $4.7 \pm 1.4$ & $4.0 \pm 1.2$ & 0.15 \\
\hline$T \mathrm{~L}, \mathrm{CO} / V_{A} \mathrm{mmol} \cdot \mathrm{min}^{-1} \cdot \mathrm{kPa}^{-1} \cdot \mathrm{L}^{-1}$ & $1.46 \pm 0.13$ & $1.48 \pm 0.13$ & 0.79 \\
\hline \multicolumn{4}{|c|}{$\begin{array}{l}\text { Data are presented as mean } \pm \mathrm{SD} \text {, unless otherwise stated. Anthropometric } \\
\text { data, values of workload and heart rate during maximum exercise in normoxia } \\
\text { and lung function parameters for subjects susceptible to high-altitude } \\
\text { pulmonary oedema (HAPE) and controls are presented. Wmax: maximum } \\
\text { workload; fC,max: maximum cardiac frequency; TLC: total lung capacity; \% } \\
\text { pred: \% predicted; VC: vital capacity; FEV1: forced expiratory volume in one } \\
\text { second; MEF50: mid-expiratory flow at } 50 \% \text { of the } V C \text {; } T L, C O \text { : transfer factor of } \\
\text { the lung for carbon monoxide; } V A \text { : alveolar volume. }\end{array}$} \\
\hline
\end{tabular}

$25 \mathrm{~W}$ and increased by $25 \mathrm{~W}$ every $2 \mathrm{~min}$ to the subject's exhaustion in normoxia or in hypoxia, until adequate tricuspid regurgitation profiles were no longer detectable. During hypoxia, measurements were recorded after 10, 60 and 120 min, when maximal PASP is expected [18]. For PASP determination, peak-flow velocities of tricuspid valve regurgitation jets were measured at the highest coherent boundary of the spectral wave using continuous-wave Doppler, guided by colour-flow Doppler. All measurements were recorded on videotape and evaluated offline (Echo-Com; PPG Hellige $\mathrm{GmbH}$, Freiburg, Germany) in random order by an experienced sonographer blinded to clinical and experimental data. Reported values are the means of three different heart cycles. For maximum PASP during exercise, the highest measurable PASPs during the whole examination were taken.

\section{Missing values}

A total of 37 subjects were included in the study, of whom 19 were HAPE susceptible and 18 served as controls. Five subjects without tricuspid valve regurgitation had to be excluded from evaluation. During exercise in normoxia, three subjects had to be excluded due to insufficient Doppler profiles $(n=2)$ and/or exercise-induced systemic arterial hypertension (blood pressure $(\mathrm{BP})>230 / 110 \mathrm{mmHg} ; \mathrm{n}=3$ ). PASP could not be assessed in five subjects during exercise in hypoxia, as a result of insufficient Doppler profiles.

\section{Isocapnic hypoxic ventilatory response}

The detailed procedure of the HVR measurement is described elsewhere $[8,19]$. Briefly, all tests were performed at the same time under quiet conditions. During the test, subjects were breathing through a low-resistance respiratory device. Minute ventilation $\left(V^{\prime} \mathrm{E}\right)$, and partial pressures of end-tidal oxygen and carbon dioxide were determined breath by breath by an opencircuit spirometric system (Oxycon Beta; Mijnhardt, Bunnik, The Netherlands). Simultaneously, arterial oxygen saturation 
$\left(\mathrm{Sa}, \mathrm{O}_{2}\right)$ was recorded using a pulse oximeter (3900 Biox Pulse Oxymeter; Datex-Ohmeda, Helsinki, Finland). After complete oxygen saturation was achieved by breathing a hyperoxic gas mixture $\left(35 \% \mathrm{O}_{2}, 65 \% \mathrm{~N}_{2}\right)$ from a reservoir, $\mathrm{FI}_{1} \mathrm{O}_{2}$ was progressively reduced over 7-10 min by admixture of pure nitrogen, until an $\mathrm{Sa}_{\mathrm{a}} \mathrm{O}_{2}$ of $80 \%$ was reached.

\section{Lung function testing}

Standard lung function testing was performed using a body plethysmograph (Universal Bodytest; Jäger, Würzburg, Germany) to assess spirometry and diffusion capacity.

\section{Statistics}

Data are reported as mean \pm SD. Differences between groups were analysed by unpaired t-test with unequal variances. Differences of the means are given with the respective $95 \%$ confidence interval and $t$-value (difference of the means divided by the SD). In a sample of $\sim 30$ subjects, a $t$-value $>2$ means that the observed difference is also of relevance. Changes within the same group were tested by paired t-test. Differences in sensitivity and specificity were compared by McNemar's test. Effects of additional examinations (HVR, lung function) on identification of HAPE susceptibility were evaluated by a multiple logistic regression model. All cut-off levels were calculated by maximising Youden's index. Correlations between PASP measurements at rest in hypoxia, exercise in normoxia and exercise in hypoxia, respectively, were calculated with Pearson's correlation. The level of significance was set at $\mathrm{p} \leqslant 0.05$.

\section{RESULTS}

\section{Study population}

Since some subjects had to be excluded from evaluation due to reasons mentioned in the Methods section, analysis is based on 17 HAPE-susceptible subjects versus 15 controls for rest in normoxia and hypoxia, 16 versus 13 subjects for normoxic exercise, and 13 versus 11 subjects during exercise in hypoxia. Characteristics of the subjects are presented in table 1 . There were no significant differences in anthropometric data between the two groups. All subjects showed spirometric values within the normal range without any group differences.

\section{Pulmonary artery systolic pressure response}

There were no group differences in heart rate, $\mathrm{BP}$ or $\mathrm{Sa}_{1} \mathrm{O}_{2}$ at baseline, during hypoxic exposure or exercise. During exercise in normoxia, as well as in hypoxia, there were also no differences in workload. In hypoxia, exercise was ended in all cases before subjects reached the limit of tolerance due to inadequate Doppler signals. At baseline, PASP was similar for both groups, there were no signs of left or right ventricular dysfunction and there was no difference in pulmonary acceleration time at rest. During all study conditions, PASP was significantly higher in the HAPE-susceptible subjects compared with controls. The difference of means was $19.5 \mathrm{mmHg}$ during exercise in normoxia (95\% confidence interval (CI) 10.9-28.0; $t=4.7$ ). During hypoxia at rest, the difference was already significant after $10 \mathrm{~min}(\mathrm{p}=0.01$; fig. 1$)$ and reached the maximum after $120 \mathrm{~min}$ (difference of means $10.9 \mathrm{mmHg} ; 95 \%$ CI 5.2-16.6; $\mathrm{t}=3.9$ ). During exercise in hypoxia, all except two subjects reached their highest PASP (difference of means $20.0 \mathrm{mmHg}$; 95\% CI 10.6-29.4; $\mathrm{t}=4.4$ ).

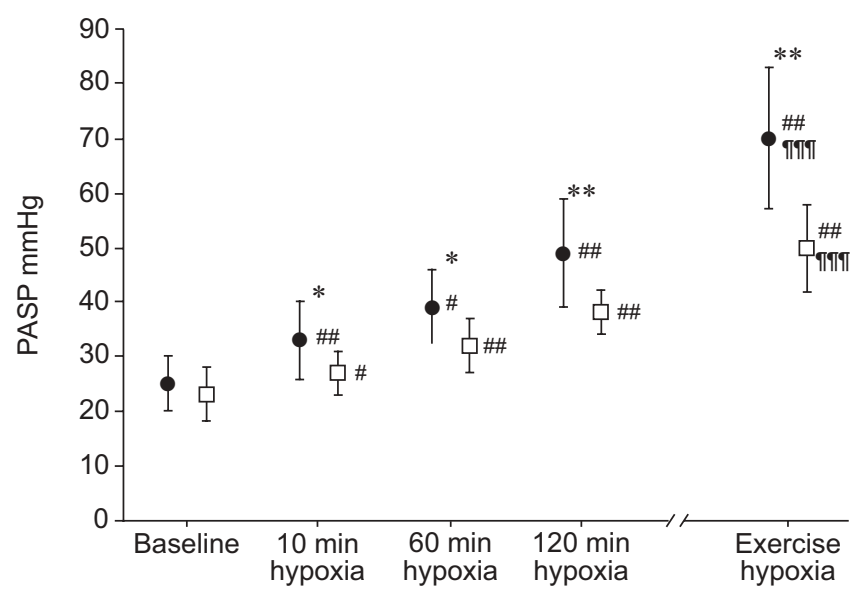

FIGURE 1. Pulmonary artery systolic pressure (PASP) at baseline, during hypoxic exposure and maximal values during exercise in hypoxia for subjects susceptible to high-altitude pulmonary oedema (HAPE; - versus controls ( $\square$ ) Data are expressed as mean \pm SD. Significances are expressed as the difference between HAPE-susceptible subjects versus control $\left(^{*}\right)$, the difference versus baseline $(\#)$, and the difference versus 120 min hypoxia $\left({ }^{\star}\right)$. One symbol: $p<0.05$ two symbols: $p<0.01$; three symbols: $p<0.001$

Group data of PASP are presented in table 2; individual PASPs are shown in figures 2 and 3.

\section{Cut-off values}

The Youden's index was highest for a cut-off value at $41 \mathrm{mmHg}$ at hypoxia, ranging $39-42 \mathrm{mmHg}$ for exercise in

TABLE 2 Response to hypoxia and to exercise

Rest

Exercise at PASPmax

Normoxia Hypoxia p-value Normoxia Hypoxia p-value

fC $\mathrm{min}^{-1}$

$\begin{array}{lccccc}\text { HAPE susceptible } & 64 \pm 11 & 64 \pm 11 & 137 \pm 17 & 117 \pm 8 & <0.001 \\ \text { Controls } & 67 \pm 8 & 69 \pm 11 & 141 \pm 16 & 117 \pm 15 & <0.001 \\ \text { p-value } & 0.33 & 0.20 & 0.48 & 0.97 & \end{array}$

$\mathrm{Sa}, \mathrm{O}_{2} \%$

HAPE susceptible $98 \pm 1 \quad 75 \pm 9 \quad<0.001 \quad 96 \pm 2 \quad 69 \pm 7<0.001$

$\begin{array}{lllllll}\text { Controls } & 98 \pm 1 & 78 \pm 8 & <0.001 & 97 \pm 2 & 72 \pm 5 & <0.001\end{array}$

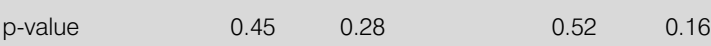

PASP $\mathbf{m m H g}$

HAPE susceptible $\quad 25 \pm 5 \quad 48 \pm 10<0.001 \quad 57 \pm 14 \quad 69 \pm 13<0.001$

$\begin{array}{lllllll}\text { Controls } & 23 \pm 5 & 38 \pm 3 & <0.001 & 38 \pm 7 & 49 \pm 8 & <0.01\end{array}$

p-value $\quad 0.42<0.001<0.001<0.001$

$\mathbf{W} \mathbf{W} \cdot \mathbf{k g}^{-1}$

HAPE susceptible $\quad 2.4 \pm 0.5 \quad 1.2 \pm 0.3<0.001$

Controls

$2.3 \pm 0.5 \quad 1.1 \pm 0.4<0.001$

p-value

$0.56 \quad 0.33$

Data are presented as mean $\pm \mathrm{SD}$. PASPmax: maximum pulmonary artery systolic pressure; $f C$ : cardiac frequency; HAPE: high-altitude pulmonary oedema; $\mathrm{Sa}_{2} \mathrm{O}_{2}$ : arterial oxygen saturation; PASP: pulmonary artery systolic pressure; W: workload. Significances from normoxic to hypoxic condition and differences between subjects susceptible to HAPE and controls are indicated. 

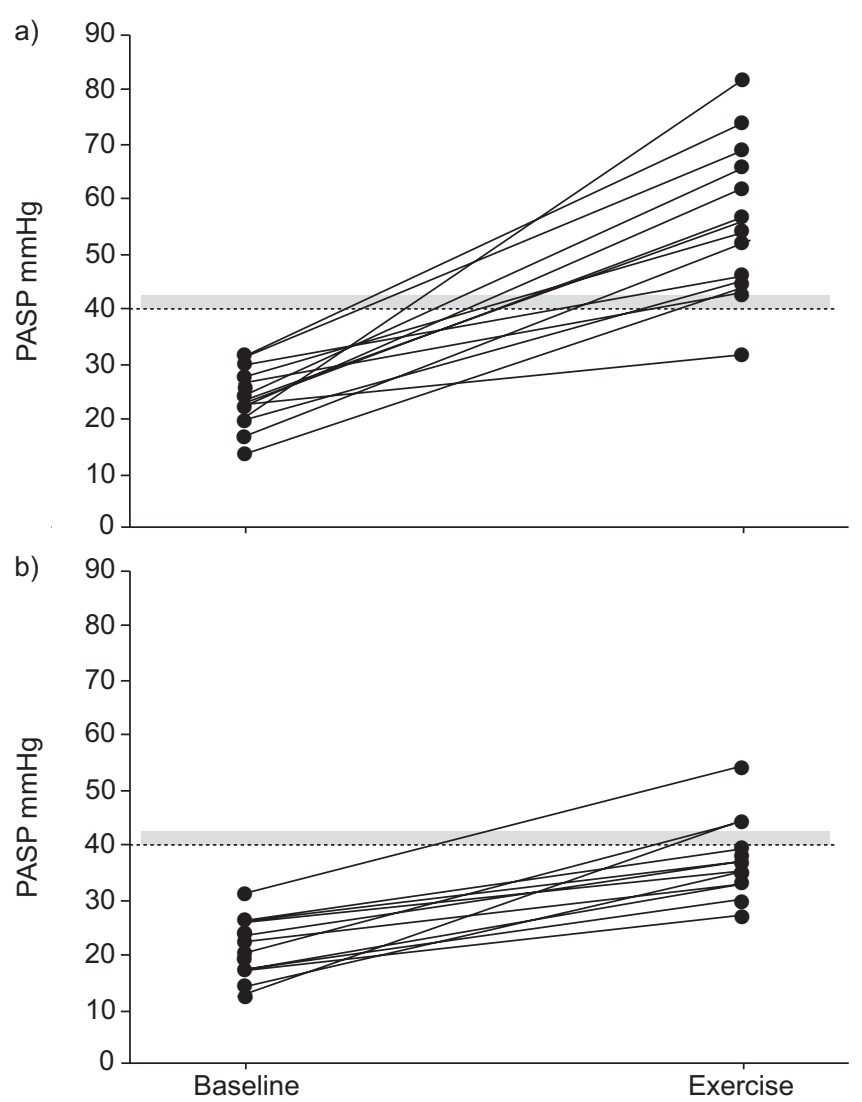

FIGURE 2. Individual pulmonary artery systolic pressure (PASP) values for a) subjects susceptible to high-altitude pulmonary oedema (HAPE) and b) controls at baseline and maximum value during exercise. The grey bar indicates the range for optimal differentiation between HAPE-susceptible subjects and controls. The previously used cut-off level of $40 \mathrm{mmHg}$ is indicated by the dotted line.

normoxia and $52 \mathrm{mmHg}$ during exercise in hypoxia, respectively. Numbers of wrongly classified subjects, values for sensitivity and specificity, and positive and negative predictive values for the respective cut-off levels revealed similar diagnostic values for all conditions (table 3). Positive and negative predictive values are based on a prevalence of HAPE susceptibility of $9.7 \%$, which is given by the overall prevalence of HAPE of $6 \%$ and a recurrence rate of $62 \%$ for susceptible subjects after rapid ascent to $4,559 \mathrm{~m} \mathrm{[1]}$.

\section{Isocapnic hypoxic ventilatory response}

HVR could not be assessed in two subjects from the control group due to technical difficulties. There was no group difference between both groups (mean \pm SD $0.78 \pm$ $0.28 \mathrm{~L} \cdot \mathrm{min}^{-1} \cdot \%^{-1}$ versus $\left.0.90 \pm 0.38 \mathrm{~L} \cdot \mathrm{min}^{-1} \cdot \%{ }^{-1} ; \mathrm{p}=0.34\right)$. Since subjects susceptible to acute mountain sickness are known to have widespread values for HVR, five subjects from the control group with severe acute mountain sickness in their history were eliminated. When this subgroup with good altitude tolerance $(n=8)$ was compared with HAPE-susceptible subjects, there was a tendency for higher values in the control group $\left(1.04 \pm 0.39 \mathrm{~L} \cdot \mathrm{min}^{-1} \cdot \%{ }^{-1} ; \mathrm{p}=0.07\right)$, which, however, did not reach the level of statistical significance.
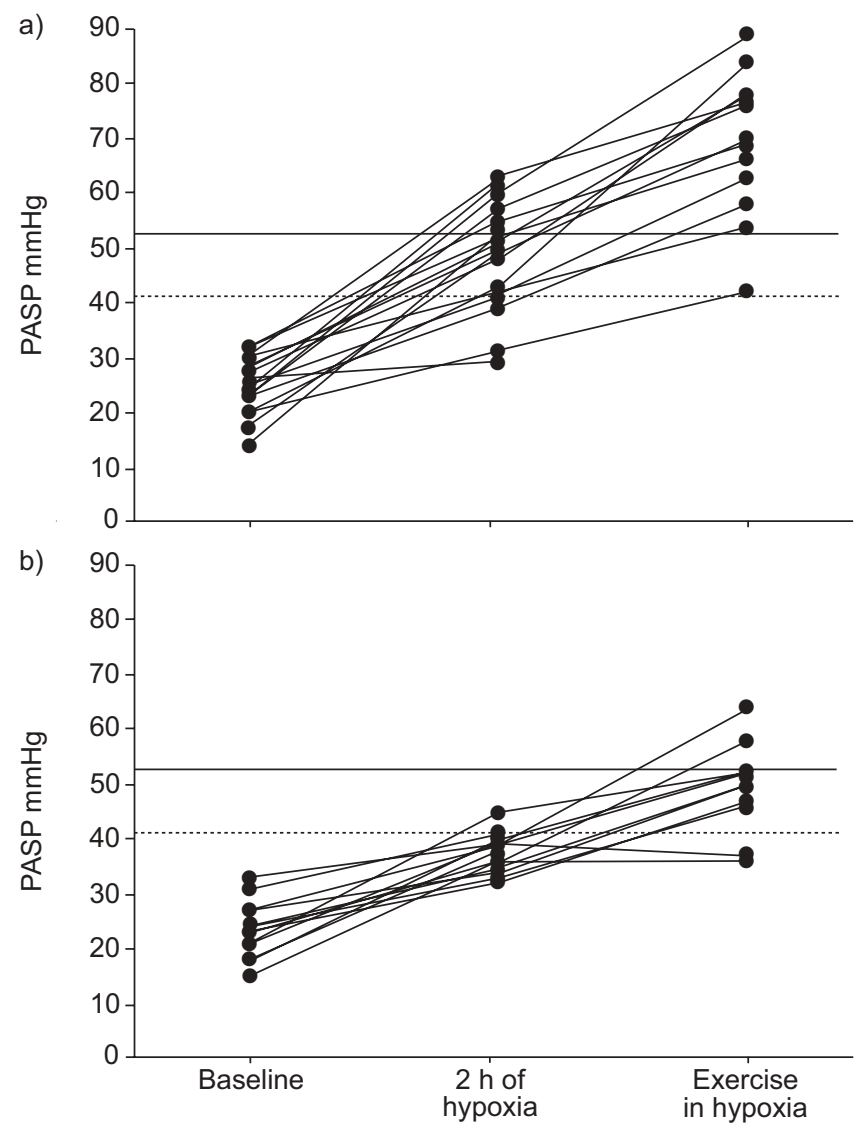

FIGURE 3. Individual pulmonary artery systolic pressure (PASP) values for a) subjects susceptible to high-altitude pulmonary oedema (HAPE) and b) controls at baseline after $2 \mathrm{~h}$ of hypoxic exposure and maximum value during exercise in hypoxia. Lines indicate cut-off levels for optimal differentiation between HAPEsusceptible subjects and controls. Cut-off levels were $41 \mathrm{mmHg}$ after $2 \mathrm{~h}$ hypoxia (dotted line) and $52 \mathrm{mmHg}$ during hypoxic exercise (solid line).

\section{Correlations and logistic regression}

Prediction of HAPE susceptibility could not be improved by combination of PASP measurements under different conditions. The odds ratios for HAPE susceptibility were 28.0 (CI

\section{TABLE 3 Comparison of different conditions}

\begin{tabular}{lccc} 
& $\begin{array}{c}\text { Rest } \\
\text { hypoxia }\end{array}$ & $\begin{array}{c}\text { Exercise } \\
\text { normoxia }\end{array}$ & $\begin{array}{c}\text { Exercise } \\
\text { hypoxia }\end{array}$ \\
\hline Cut-off value/range $\mathbf{m m H g}$ & 41 & $39-43$ & 52 \\
Wrongly classified subjects & 5 & 4 & 3 \\
Correctly classified subjects & 27 & 25 & 21 \\
Sensitivity \% & 77 & 94 & 92 \\
Specificity \% & 93 & 77 & 82 \\
Positive predictive value \% & 56 & 30 & 35 \\
Negative predictive value \% & 97 & 99 & 99 \\
Missing values & $5(14)$ & $8(22)$ & 13 (35) \\
\hline & & &
\end{tabular}


4.0-196.5; $\mathrm{p}<0.001)$ for hypoxia, 50.0 (CI 4.5-551.4; $\mathrm{p}=0.001)$ for exercise in normoxia and 54.0 (CI 4.2-692.5; $\mathrm{p}=0.002$ ) for exercise in hypoxia if the respective PASP was above the evaluated cut-off level. Correlation coefficients for PASP assessment under different conditions were $0.57 \quad\left(\mathrm{r}^{2}=0.32\right.$; $\mathrm{p}=0.002$ ) between hypoxia and exercise in normoxia, 0.83 $\left(\mathrm{r}^{2}=0.69 ; \mathrm{p}<0.001\right)$ between hypoxia and exercise in hypoxia and $0.63\left(r^{2}=0.40 ; p<0.001\right)$ between exercise in normoxia and exercise in hypoxia. For the identification of HAPE-susceptible subjects, multiple logistic regressions revealed no improvement by inclusion of HVR or any lung function parameter because of the dominance of PASP measurements.

\section{DISCUSSION}

This study demonstrates that the addition of exercise to hypoxia does not improve the identification of individuals susceptible to HAPE compared with PASP measurements after $2 \mathrm{~h}$ of hypoxia or exercise in normoxia alone. HVR and lung volume measurements add no information on HAPE susceptibility because PASP response is the most important variable. Furthermore, the current study confirms previously established cut-off levels for pulmonary artery pressure rise in hypoxia and in normoxic exercise in a larger group, and shows that the specificity and sensitivity of an abnormal PASP rise with hypoxia or normoxic exercise are in the order of $80-90 \%$.

\section{Pulmonary vascular response}

PASP at baseline in all subjects was within the normal range. The present authors assumed the right atrial pressure to be $5 \mathrm{mmHg}$, since all subjects had normal vena cava diameters and respiratory variability. The current upper limit of normal values (PASP $41 \mathrm{mmHg}$ ) agrees well with a study establishing normal values in a large number of subjects when one considers that these investigators assumed the right atrial pressure to be $10 \mathrm{mmHg}$ [20]. Furthermore, the current measurements are in agreement with other studies assessing PASP at rest and during exercise [20-24].

PASP measurements during hypoxic exposure showed a significantly greater increase in HAPE-susceptible subjects consistent with previous studies in which PASP was obtained either by echocardiography [7, 21, 22] or by right-heart catheterisation $[5,6,9,15]$. However, in a previous study with a similar design, there was a large overlap between HAPEsusceptible and nonsusceptible subjects in PASP during hypoxia [8]. This discrepancy may, in part, be attributed to the duration of the hypoxic exposure $(15 \mathrm{~min}$ in the previous [8] versus $2 \mathrm{~h}$ in the present study) and the random exposure to two different hypoxic gas mixtures. DORRINGTON et al. [18] clearly demonstrated by right-heart catheterisation in healthy males that maximum pulmonary artery pressure and also pulmonary vascular resistance are not reached before $2 \mathrm{~h}$ of hypoxic exposure. A comparable time course of PASP was shown in the current study. Although the difference between groups was significant after $10 \mathrm{~min}$ of hypoxic exposure, in both groups, PASP increased and the number of overlapping values decreased during the $2 \mathrm{~h}$ of hypoxic exposure (fig. 1).

The increased PASP response to exercise during normoxia in individuals susceptible to HAPE could also be confirmed [7, 9]. However, noninvasive measurements of PASP provide some limitations, especially during exercise. In addition, echocardiographic estimation of cardiac output during exercise is often inaccurate. Nevertheless, it is unlikely that differences in PASP between HAPE-susceptible subjects and controls during exercise can be attributed to differences in cardiac output, since, in studies measuring cardiac output invasively, no differences were found between subjects susceptible to HAPE and healthy controls $[6,9]$. Therefore, these parameters were not assessed in the present study.

The calculation of the best PASP cut-off level, as described in the Methods section, yielded a value of $41 \mathrm{mmHg}$ for hypoxic exposure and a range of $39-42 \mathrm{mmHg}$ during exercise in normoxia. These values are almost identical to the cut-off values used in a previous study [7], which were based on the upper limit of normal values reported in the literature for exercise in normoxia [23, 24] or hypoxic exposure [21]. These results suggest that the limit of normal pulmonary vascular response for normoxic exercise and for acute exposure to hypoxia equivalent to an altitude of $4,500 \mathrm{~m}$ is $\sim 40 \mathrm{mmHg}$ for systolic PASP. However, it should also be pointed out that there is some overlap, as shown by NAEIJE et al. [25] and by the present study.

The response to exercise during hypoxia was comparable with data reported in the literature $[9,26,27]$. The increase of PASP when going from rest to exercise in hypoxia was comparable between HAPE-susceptible and nonsusceptible individuals. This suggests that hypoxia and exercise have additive effects on PASP that are of the same order of magnitude. Therefore, assessment of PASP during hypoxic exercise does not increase the discrimination between groups. The optimal cut-off level is $\sim 10 \mathrm{mmHg}$ higher than in hypoxia at rest or exercise in normoxia.

The small number of subjects wrongly classified resulted in comparable sensitivity and specificity of $80-90 \%$ for all conditions (table 3), which, for example, is better than exercise ECG for detection of coronary artery disease. If echocardiographic assessment of PASP is possible in an individual, it provides a useful tool for the identification of subjects susceptible to HAPE. However, it has to be considered that PASP could not be measured in $\sim 14 \%$ of the subjects during resting conditions and $35 \%$ during exercise in normoxia. During exercise in hypoxia, the proportion of subjects with inadequate Doppler signals is even higher, due to a greater increase in ventilation and heart rate. Thus, examinations performed at rest in hypoxia and during exercise in normoxia may be the most efficient and practical approaches to detect abnormal pulmonary vascular response in HAPE-susceptible individuals.

\section{Hypoxic ventilatory response and lung volume}

A significant difference of HVR between HAPE-susceptible individuals and controls was not found. This may be due to several reasons. First, there is a variable degree of susceptibility to acute mountain sickness in the current subjects. Others have shown that individuals not susceptible to acute mountain sickness have a higher HVR than those who are susceptible to acute mountain sickness [28] or to HAPE [8]. If only subjects without a history of severe acute mountain sickness from the control group were compared with 
HAPE-susceptible subjects, HVR was almost significantly lower $(p=0.07)$ in HAPE-susceptible subjects. In addition, there may be confounding effects of sex and age. Since female subjects were not examined during the same phase of the menstrual cycle, and since there was a higher mean age than in previous studies [8, 12, 13], it is suggested that these potentially confounding factors [29-31] may account, in part, for the negative finding regarding the association between HVR and HAPE susceptibility. From a practical point of view, all those confounders are present in daily practice. Therefore, the addition of HVR measurements does not improve the identification of individuals susceptible to HAPE. Even in a setting with significant difference of HVR between controls and HAPE-susceptible subjects, the present authors would not expect to see a large effect of an additional parameter for the identification of susceptibility to HAPE, since the specificity and sensitivity of PASP measurements are already very high.

The same conclusion applies to lung function parameters, although there is no explanation for why smaller lung volumes could not be found, as previously reported [9, 14-16]. Nevertheless, the assessment of lung function is useful, especially in subjects with an elevated PASP response to exercise to exclude underlying restrictive or obstructive lung disease.

\section{Testing for high-altitude pulmonary oedema susceptibility}

Based on this investigation, it is concluded that general screening for susceptibility to HAPE in people climbing to high altitude with unknown altitude tolerance cannot be recommended, even when applying the most effective methods established in the current study, which consisted of PASP assessment at rest after $2 \mathrm{~h}$ of hypoxic exposure at an $\mathrm{FI}_{1} \mathrm{O}_{2}$ of 0.12 or during normoxic exercise. The low prevalence of HAPE in mountaineers at 4,500 $\mathrm{m}$ of $0.2-6.0 \%$ [1] and the prevalence of $\sim 9-10 \%$ of an abnormal PASP response to hypoxia in healthy subjects [32] precludes general screening not only for economical reasons. Given specificities and sensitivities of between $77 \%$ and $94 \%$ of these methods (table 3), screening in a large unselected population will yield more false-positive than true-positive HAPE-susceptible individuals. However, testing might be useful in special situations, such as, for example, a questionable previous episode in a person who wants to go on a mountain expedition. A PASP value $<40 \mathrm{mmHg}$ in such an individual rules out susceptibility to HAPE (negative predictive value 97\%), while an increased hypoxic pulmonary vascular response is less conclusive (positive predictive value of $56 \%$ ). If PASP is $>40 \mathrm{mmHg}$, in combination with a history compatible with HAPE, susceptibility should be assumed.

Finally, the authors would like to draw attention to two cases reported a few years ago that demonstrate that a true resistance to HAPE might not exist [33]. HAPE, which was lethal in one case, occurred after an ascent within 9 days to $7,200 \mathrm{~m}$ and 14 days to $8,400 \mathrm{~m}$ in individuals who had proved their altitude tolerance by several previous exposures above $8,000 \mathrm{~m}$. These cases demonstrate that probably anybody can get HAPE if they go high enough and fast enough.

Thus, independent of the "assigned" risk class, the following basic rules to avoid severe-acute mountain sickness and high-altitude pulmonary oedema must be adhered to in the field: never ascend to a higher sleeping altitude with symptoms of acute mountain sickness, and descend when these symptoms do not improve within a day of rest. In the presence of symptoms suggestive of early high-altitude pulmonary oedema, descent should be undertaken immediately.

\section{ACKNOWLEDGEMENTS}

The authors would like to thank V. Henschel from the Institute of Medical Biometry, University of Heidelberg, Heidelberg, Germany, for his assistance and revision of the statistics section, and E. Menold from the Division of Sports Medicine, University of Heidelberg, for his excellent technical assistance. We also thank A. Benz and A. Schoene from the Dept of Cardiology, University of Heidelberg, for their help with the echocardiography and for performing the pulmonary function tests, respectively.

\section{REFERENCES}

1 Bärtsch $P$, Maggiorini $M$, Mairbaurl H, Vock $P$, Swenson ER. Pulmonary extravascular fluid accumulation in climbers. Lancet 2002; 360: 571.

2 Hultgren HN, Lopez CE, Lundberg E, Miller $H$. Physiologic studies of pulmonary edema at high altitude. Circulation 1964; 29: 393-408.

3 Maggiorini M, Melot C, Pierre S, et al. High-altitude pulmonary edema is initially caused by an increase in capillary pressure. Circulation 2001; 103: 2078-2083.

4 Bärtsch P, Maggiorini M, Ritter M, Noti C, Vock P, Oelz O. Prevention of high-altitude pulmonary edema by nifedipine. N Engl J Med 1991; 325: 1284-1289.

5 Hultgren HN, Grover RF, Hartley LH. Abnormal circulatory responses to high altitude in subjects with a previous history of high-altitude pulmonary edema. Circulation 1971; 44: 759-770.

6 Kawashima A, Kubo K, Kobayashi T, Sekiguchi M. Hemodynamic responses to acute hypoxia, hypobaria, and exercise in subjects susceptible to high-altitude pulmonary edema. J Appl Physiol 1989; 67: 1982-1989.

7 Grünig E, Mereles D, Hildebrandt W, et al. Stress Doppler echocardiography for identification of susceptibility to high altitude pulmonary edema. J Am Coll Cardiol 2000; 35: 980-987.

8 Hohenhaus E, Paul A, McCullough RE, Kucherer H, Bärtsch P. Ventilatory and pulmonary vascular response to hypoxia and susceptibility to high altitude pulmonary oedema. Eur Respir J 1995; 8: 1825-1833.

9 Eldridge MW, Podolsky A, Richardson RS, et al. Pulmonary hemodynamic response to exercise in subjects with prior high-altitude pulmonary edema. J Appl Physiol 1996; 81: 911-921.

10 Oelz O, Maggiorini M, Ritter M, et al. Nifedipine for high altitude pulmonary oedema. Lancet 1989; 2: 1241-1244.

11 Scherrer U, Vollenweider L, Delabays A, et al. Inhaled nitric oxide for high-altitude pulmonary edema. $N$ Engl J Med 1996; 334: 624-629.

12 Matsuzawa Y, Fujimoto K, Kobayashi T, et al. Blunted hypoxic ventilatory drive in subjects susceptible to highaltitude pulmonary edema. J Appl Physiol 1989; 66: 1152-1157. 
13 Hackett PH, Roach RC, Schoene RB, Harrison GL, Mills WJ Jr. Abnormal control of ventilation in high-altitude pulmonary edema. J Appl Physiol 1988; 64: 1268-1272.

14 Selland MA, Stelzner TJ, Stevens T, Mazzeo RS, McCullough RE, Reeves JT. Pulmonary function and hypoxic ventilatory response in subjects susceptible to high-altitude pulmonary edema. Chest 1993; 103: 111-116.

15 Viswanathan R, Jain SK, Subramanian S, Subramanian TA, Dua GL, Giri J. Pulmonary edema of high altitude. II. Clinical, aerohemodynamic, and biochemical studies in a group with history of pulmonary edema of high altitude. Am Rev Respir Dis 1969; 100: 334-341.

16 Steinacker JM, Tobias P, Menold E, et al. Lung diffusing capacity and exercise in subjects with previous high altitude pulmonary oedema. Eur Respir J 1998; 11: 643-650.

17 Allemann Y, Sartori C, Lepori M, et al. Echocardiographic and invasive measurements of pulmonary artery pressure correlate closely at high altitude. Am J Physiol Heart Circ Physiol 2000; 279: H2013-H2016.

18 Dorrington KL, Clar C, Young JD, Jonas M, Tansley JG, Robbins PA. Time course of the human pulmonary vascular response to 8 hours of isocapnic hypoxia. Am J Physiol 1997; 273: H1126-H1134.

19 Rebuck AS, Campbell EJ. A clinical method for assessing the ventilatory response to hypoxia. Am Rev Respir Dis 1974; 109: 345-350.

20 McQuillan BM, Picard HM, Leavitt M, Weyman AE. Clinical correlates and reference intervals for pulmonary artery systolic pressure among echocardiographically normal subjects. Circulation 2001; 104: 2797-2802.

21 Yagi H, Yamada H, Kobayashi T, Sekiguchi M. Doppler assessment of pulmonary hypertension induced by hypoxic breathing in subjects susceptible to high altitude pulmonary edema. Am Rev Respir Dis 1990; 142: 796-801.

22 Vachiery JL, McDonagh T, Moraine JJ, et al. Doppler assessment of hypoxic pulmonary vasoconstriction and susceptibility to high altitude pulmonary oedema. Thorax 1995; 50: 22-27.

23 Gurtner HP, Walser P, Fässler B. Normal values for pulmonary hemodynamics at rest and during exercise in man. Prog Resp Res 1975; 9: 295-315.

24 Janosi A, Apor P, Hankoczy J, Kadar A. Pulmonary artery pressure and oxygen consumption measurement during supine bicycle exercise. Chest 1988; 93: 419-421.

25 Naeije R, Melot C, Lejeune P. Hypoxic pulmonary vasoconstriction and high altitude pulmonary edema. Am Rev Respir Dis 1986; 134: 332-333.

26 Wagner PD, Gale GE, Moon RE, Torre-Bueno JR, Stolp BW, Saltzman HA. Pulmonary gas exchange in humans exercising at sea level and simulated altitude. J Appl Physiol 1986; 61: 260-270.

27 Groves BM, Reeves TJ, Sutton JR, et al. Operation Everest II: elevated high-altitude pulmonary resistance unresponsive to oxygen. J Appl Physiol 1987; 63: 521-530.

28 Moore LG, Harrison GL, McCullough RE, et al. Low acute hypoxic ventilatory response and hypoxic depression in acute altitude sickness. J Appl Physiol 1986; 60: 1407-1412.

29 Peterson DD, Pack AI, Silage DA, Fishman AP. Effects of aging on ventilatory and occlusion pressure responses to hypoxia and hypercapnia. Am Rev Respir Dis 1981; 124: 387-391.

30 Bayliss DA, Millhorn DE. Central neural mechanisms of progesterone action: application to the respiratory system. J Appl Physiol 1992; 73: 393-404.

31 White DP, Douglas NJ, Pickett CK, Weil JV, Zwillich CW. Sexual influence on the control of breathing. J Appl Physiol 1983; 54: 874-889.

32 Grünig E, Koehler R, Miltenberger-Miltenyi G, et al. Primary pulmonary hypertension in children may have a different genetic background than in adults. Pediatr Res 2004; 56: 571-578.

33 Bärtsch P. High altitude pulmonary edema. Med Sci Sports Exerc 1999; 31: Suppl. 1, S23-S27. 